\title{
Enhanced salt tolerance in tomato plants constitutively expressing heat-shock protein in the endoplasmic reticulum
}

\author{
C. Fu, X.X. Liu, W.W. Yang, C.M. Zhao and J. Liu \\ Shandong Provincial Key Laboratory of Plant Stress Research, \\ College of Life Science, Shandong Normal University, Jinan, Shandong, China \\ Corresponding author: J. Liu \\ E-mail: 1j1sd2002@ aliyun.com
}

Genet. Mol. Res. 15 (2): gmr.15028301

Received December 17, 2015

Accepted March 21, 2016

Published July 15, 2016

DOI http://dx.doi.org/10.4238/gmr.15028301

\begin{abstract}
The accumulation of unfolded or misfolded proteins in the endoplasmic reticulum (ER) causes ER stress and activates the unfolded protein response (UPR) signaling pathway. The UPR signaling pathway is associated with plant responses to adverse environmental conditions. Thus, changes in the UPR signaling pathway might affect plant abiotic tolerance. Here, the role of ER small heat-shock protein (ER-sHSP) in improving plant resistance to salt stress was explored. Under salt stress conditions, ER-sHSP transgenic plants were found to have more vigorous roots, maintain a higher relative water content, absorb less $\mathrm{Na}^{+}$, accumulate more osmolytes and $\mathrm{Ca}^{2+}$, and sustain less damage to the photosystem, compared to wild-type non-transgenic plants. Furthermore, we found that the constitutive expression of ER-sHSP under salt stress depressed the expression of other ER molecular chaperones. These results indicate that the constitutive expression of ER-sHSP enhanced
\end{abstract}


salinity tolerance of tomato plants significantly, and alleviated the ER stress caused by the salt stress in plant cells.

Key words: Endoplasmic reticulum; Endoplasmic reticulum stress; Endoplasmic reticulum binding protein; Unfolded protein response; Endoplasmic reticulum small heat shock protein; Salt tolerance

\section{INTRODUCTION}

The synthesis of secretory and membrane proteins in the endoplasmic reticulum (ER) is a complex process regulated by a protein quality control system. A variety of molecular chaperones and foldases are involved in this system (Brodsky and McCracken, 1999; Halperin et al., 2014). Molecular chaperones, such as the ER binding protein (BiP), help newly synthesized proteins to assume their correct conformations, or associate with unrecoverable proteins to prevent them from exiting the ER until they are digested (Gething, 1999). In addition, protein disulfide isomerase (PDI), which catalyzes the formation or the rearrangement of disulfide bonds, participates in the quality control process of ER proteins (Noiva, 1999).

The concentrations of chaperones and foldases are usually adequate to deal with protein flux across the ER. In the event that protein translocation through the ER is impeded by adverse factors, the protein homeostasis in the ER will be disrupted by protein overload, causing ER stress. In response to ER stress, cells activate a protective signaling cascade, the unfolded protein response (UPR), to relieve the ER protein overload (Schröder and Kaufman, 2005; Wan and Jiang, 2015). The UPR mainly involves three steps: 1) decreasing the burden on the ER by inhibiting synthesis of secretory proteins at the translation stage; 2) inducing chaperones and foldases to assist with folding of protein and trafficking of vesicles; 3 ) accelerating degradation of unwanted, unfolded proteins (Martínez and Chrispeels, 2003).

Many factors can cause ER stress in plant cells. In the laboratory, chemical reagents, such as tunicamycin and dithiothreitol (DTT), can be applied to trigger ER stress. Under natural conditions, abiotic stresses can disturb the protein-folding process and lead to ER stress. The ER stress signal is closely connected with the signal pathway of environmental stress responses (Liu et al., 2007a; Liu and Howell, 2010). For example, salt stress leads to changes in the redox state in ER, which further regulates signaling of reactive oxygen species and triggers the antioxidant defense in Arabidopsis thaliana (Ozgur et al., 2014).

ER-residing molecular chaperones can alleviate ER stress and enhance abiotic tolerance in plants. ER BiP alleviates ER stress, confers drought tolerance, and delays drought-induced leaf senescence (Alvim et al., 2001; Valente et al., 2009). Similarly, a wheat calreticulin has been shown to relieve ER stress in tobacco cells and to improve tobacco drought tolerance (Jia et al., 2008).

Most ER-residing molecular chaperones are significantly induced by tunicamycin and DTT (Martínez and Chrispeels, 2003; Kamauchi et al., 2005), but the ER-located small heat-shock protein (hereafter ER-sHSP) is an exception (Zhao et al., 2007). ER-sHSP has the functional activity of a molecular chaperone (Zhao et al., 2007; Mamedov and Shono, 
2008) and its overexpression can alleviate ER stress caused by tunicamycin and DTT exposure (Zhao et al., 2007). The aim of this study was to determine whether the constitutive expression of ER-sHSP would improve the abiotic tolerance of plants, as does overexpression of $\mathrm{BiP}$ (Alvim et al., 2001; Valente et al., 2009) and an increased HSP90 level (Ling et al., 2014). To this end, we examined salt tolerance in transgenic tomato plants expressing ER-sHSP.

\section{MATERIAL AND METHODS}

\section{Plant material and growth conditions}

The tomato seeds used in this experiment were from the transgenic lines that contained LeERsHSP cDNA and the 35sCaMV promoter (Zhao et al., 2007). We selected LeERsHSP transgenic lines 10 (OE10) and 13 (OE13), in which the LeERsHSP protein was stably and constitutively expressed for five generations (data not shown). As controls, we used wild-type (WT) and a vector control plant with pROK II (VC). Tomato seeds were sown in moist sand pots. The pots were kept in a greenhouse at $25 / 20^{\circ} \mathrm{C}$ day/night temperatures and were irrigated with 50\% Hoagland solution twice daily. Meanwhile, the heights of plants were measured weekly, to determine the growth rate of plants. When the plants were 1 month old, salt treatments were initiated with $50 \mathrm{mM} \mathrm{NaCl}$ in $50 \%$ Hoagland solution for 4 days. Thereafter, we increased the $\mathrm{NaCl}$ concentration in $50 \%$ Hoagland solution by 50 $\mathrm{mM}$ every 4 days until the final 4-day treatment of $200 \mathrm{mM} \mathrm{NaCl}$ was completed. At this time, the overground parts and the roots of the plants were photographed, and the biomass of root was measured.

Before the beginning of salt treatment and just after the irritation of 100 and $200 \mathrm{mM}$ $\mathrm{NaCl}$, the middle leaves at half the height of the tomato plants were taken as materials for physiological measurements. From each plant, three leaves were sampled for the assay. The roots at the corresponding periods were obtained, and rinsed 3 times with distilled water, and were used as materials for ion content measurements.

\section{Relative water, chlorophyll, and ion contents}

Relative water content (RWC) was determined using the following formula: RWC (\%) $=100 \mathrm{x}$ (fresh mass - dry mass) / (turgid mass - dry mass), where turgid mass was determined after the leaf was saturated. Chlorophyll content was determined using the method described by $\mathrm{Li}$ et al. (2003). $\mathrm{K}^{+}, \mathrm{Na}^{+}$, and $\mathrm{Ca}^{2+}$ contents in tomato leaves and roots were determined using an atomic absorption spectrophotometer (Z-8000; Hitachi, Tokyo, Japan).

\section{Maximum quantum yield of photosystem II photochemistry}

We evaluated cellular damage related to photosystem activity. The maximum quantum yield of photosystem II photochemistry was measured with an FMS-2 modulated chlorophyll fluorometer (Hansatech, Kings Lynn, UK). Samples of intact leaves were inserted in leaf clips and dark-adapted for $30 \mathrm{~min}$ before the measurement of minimum fluorescence $F_{0}$. They were then exposed to saturation pulse light $\left(15,000 \mu \mathrm{mol} \cdot \mathrm{m}^{-2} \cdot \mathrm{s}^{-1}\right.$ for $\left.0.7 \mathrm{~s}\right)$, to measure maximum fluorescence $F_{m}$. The maximum quantum yield of photosystem II photochemistry is defined as $F_{v} / F_{m}$, in which $F_{v}=F_{m}-F_{0}$. 


\section{Net photosynthetic rate, stomatal conductance, transpiration rate, and soluble proline and sugar content}

Wilting is a clear symptom of damaged tomato leaves and the rate of water loss in leaves depends partly on the stomatal conductance $\left(g_{s}\right)$ and the transpiration rate. Therefore, we quantified these two physiological components in addition to net photosynthetic rate. Net photosynthetic rate, $g_{s}$, and transpiration rate were measured by IR gas analysis using a portable analyzer (CIRAS-2; PP Systems, Herts, UK) at $600 \mu \mathrm{mol} \cdot \mathrm{m}^{-2} \cdot \mathrm{s}^{-1}$ irradiance. We also measured the contents of two important osmolytes: proline and soluble sugars. Proline content was determined using a colorimetric method involving ninhydrin (Bates et al., 1973). Measurement of soluble sugar content was done following the method of Marschner et al. (1981), using an ultraviolet spectrophotometer (TU-1810; Persee, Beijing, China).

\section{Quantitative real-time polymerase chain reaction (PCR) of ER stress-related genes}

Tunicamycin- or DTT-caused ER stress can be alleviated by constitutive expression of ER-sHSP in tomato plants (Zhao et al., 2007). In this study, we investigated the effect of ER-sHSP on the UPR under salt stress. To acclimate plants to salt stress, we first irrigated 1-month-old tomato plants with $50 \mathrm{mM} \mathrm{NaCl}$ for 4 days; the plants were then exposed to $100 \mathrm{mM} \mathrm{NaCl}$. Leaf samples were collected after 0, 24, 48, and $96 \mathrm{~h}$ of $100 \mathrm{mM} \mathrm{NaCl}$ stress for quantitative real-time PCR analysis. Total RNA was isolated from these leaf samples that had been frozen in liquid nitrogen using the TRIzol reagent (Takara, Tokyo, Japan) according to manufacturer protocol and was converted into cDNA using PrimeScript RT reagent Kit (Takara). Quantitative real-time PCR was performed with SYBR Premix Ex Taq II (Takara), using a Real-Time PCR Detection System (DNA Engine Opticon 2; Bio-Rad, Hercules, CA, USA). For the quantitative real-time PCR, amplification was performed with oligonucleotides specific for the BiP, PDI, calnexin, and calreticulin genes. Amplification of the actin 7 gene was used as an internal control. Primer names and sequences are listed in Table 1.

Table 1. Sequences of quantitative real-time PCR primers.

\begin{tabular}{|c|c|c|}
\hline Primers & Sequences $\left(5^{\prime} \rightarrow 3^{\prime}\right)$ & GenBank accession number \\
\hline BiP-F & gaagcacttgaatggttggacg & \multirow[t]{2}{*}{ XM_004234937 } \\
\hline BiP-R & gccgtgataactgggttgca & \\
\hline PDI-F & acaagctccaggcaagtgaga & \multirow[t]{2}{*}{ XM_004241984 } \\
\hline PDI-R & tgattacagactagggtaagaagggt & \\
\hline calnexin-F & cctgctagagctagtgccgagac & \multirow[t]{2}{*}{ AB218598 } \\
\hline calnexin-R & gcatcctcactctgctcttccttc & \\
\hline calreticulin-F & ttattagtgaattagtagcccettcc & \multirow[t]{2}{*}{ XM_004230251 } \\
\hline calreticulin- $\mathrm{R}$ & gacatcaaagcaatcagccata & \\
\hline actin7-F & attgecctcttctgtctggetacac & \multirow[t]{2}{*}{ XM_004235020 } \\
\hline actin7-R & agacgaggagaaaacatcacaatcac & \\
\hline
\end{tabular}

\section{Statistical analysis}

All the experiments were performed using three independent biological replicates, and all values are reported as means \pm SD. Statistical analysis was performed using the SPSS 16.0 software with the Duncan multiple range test $(\mathrm{P} \leq 0.05)$. 


\section{RESULTS}

When the tomato plants were irrigated with 50\% Hoagland solution, transgenic plants (hereafter abbreviated OE lines) and the control plants grew normally and at the same rate (data not shown). This indicated that the constitutive expression of ER-sHSP did not affect normal development of the tomato plants.

Following the two final 4-day treatments of 150 and $200 \mathrm{mM} \mathrm{NaCl}$ solutions, respectively, the control plants displayed damage. The most expanded leaves had withered and turned yellow and the top leaves were slightly wilted. In contrast, the expanded leaves in the OE lines crumpled slightly but their color remained green (Figure 1A). The roots of the OE lines appeared more vigorous (Figure 1B) and root biomass was $>30 \%$ greater than the control plants (Figure 1C).

A

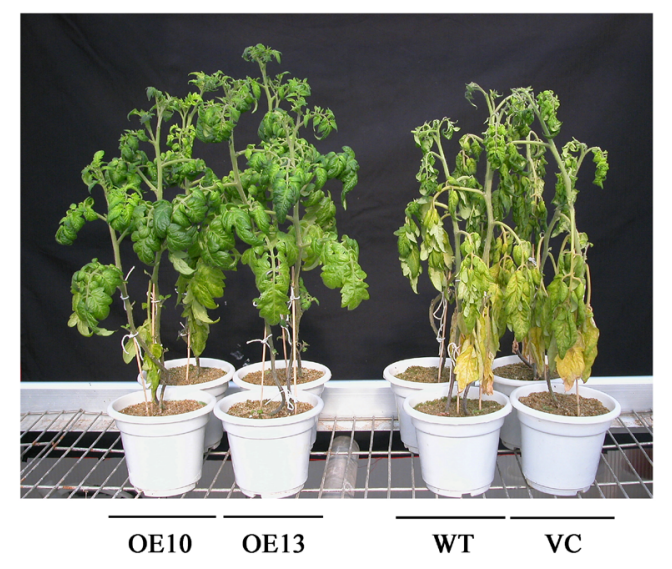

B

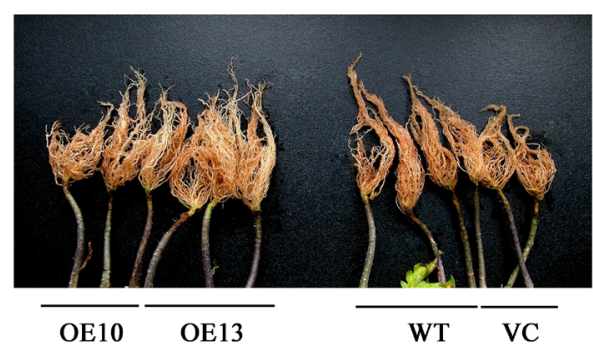

C

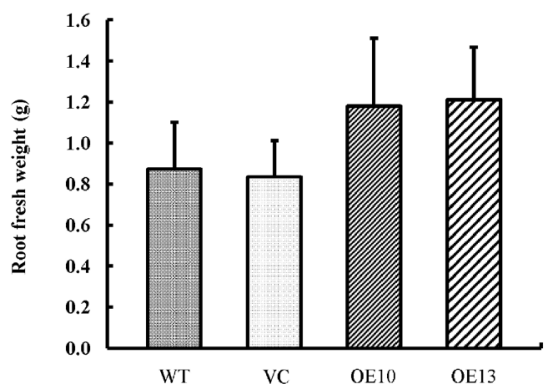

Figure 1. Tomato plants with constitutive expressed ER-sHSP exhibited improved tolerance to salt. A. Phenotype of tomato plants after a series of $\mathrm{NaCl}$ treatments. B. Roots of transgenic tomato plants are more vigorous than control plants. C. Root biomass of transgenic tomato and control plants. Values are reported as means \pm SD from three replicates. $\mathrm{OE}=$ transgenic plants; $\mathrm{WT}=$ wild-type plants; $\mathrm{VC}=$ vector control plants.

Following the first 4-day treatment with $50 \mathrm{mM} \mathrm{NaCl}$ solution, no visible damage was evident in any plant (including OE lines, WT, and VC) (data not shown). The subsequent 4-day treatment with $100 \mathrm{mM} \mathrm{NaCl}$ solution caused the chlorophyll and RWC of the control (WT and VC) plants to decline significantly compared with the OE lines (Figure 2). During the 200 $\mathrm{mM} \mathrm{NaCl}$ treatment period both chlorophyll and RWC in the leaves of the OE lines declined more slowly compared to the control plants (Figure 2). The phenotypic and physiological data all indicated that the OE lines had superior tolerance to salt stress. 


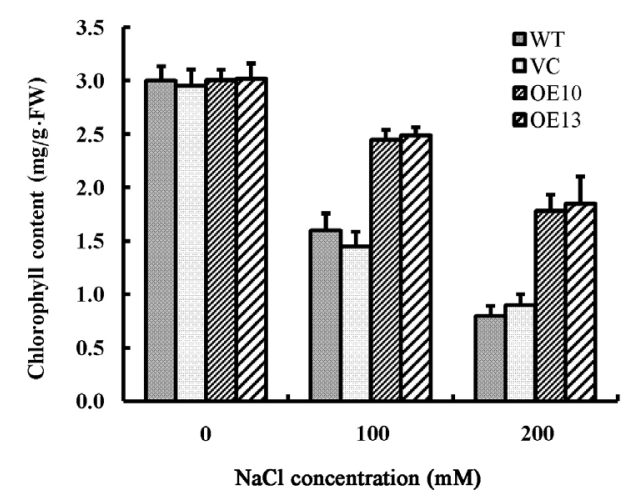

B

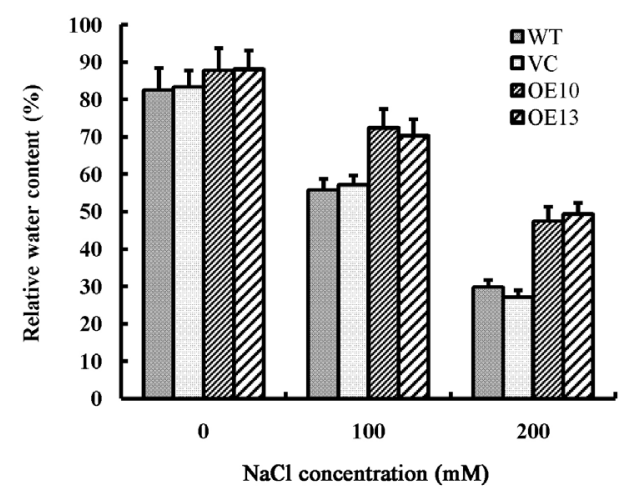

Figure 2. Effects of $\mathrm{NaCl}$ treatment on relative chlorophyll (A) and relative water (B) content in tomato leaves. Values are reported as means \pm SD from three replicates. $\mathrm{FW}=$ fresh weight. For other abbreviations, see legend to Figure 1.

The plant ion $\left(\mathrm{Na}^{+}, \mathrm{K}^{+}\right.$, and $\left.\mathrm{Ca}^{2+}\right)$ levels were greatly affected by salt stress (Figure 3). After treatment of $100 \mathrm{mM} \mathrm{NaCl}$, the tissues of the $\mathrm{OE}$ lines, including leaves and roots, accumulated more $\mathrm{K}^{+}$and $\mathrm{Ca}^{2+}$, but less $\mathrm{Na}^{+}$, compared to the control lines. Likewise, the ratio of $\mathrm{K}^{+} / \mathrm{Na}^{+}$in $\mathrm{OE}$ lines was significantly higher than that in control plants (Figure 3). At the end of the $200 \mathrm{mM} \mathrm{NaCl}$ treatment, the ion level differences were greater than at the lower $\mathrm{NaCl}$ exposures. All ion data consistently indicated that the OE lines absorbed less $\mathrm{Na}^{+}$, and had higher levels of $\mathrm{K}^{+}$and $\mathrm{Ca}^{2+}$.

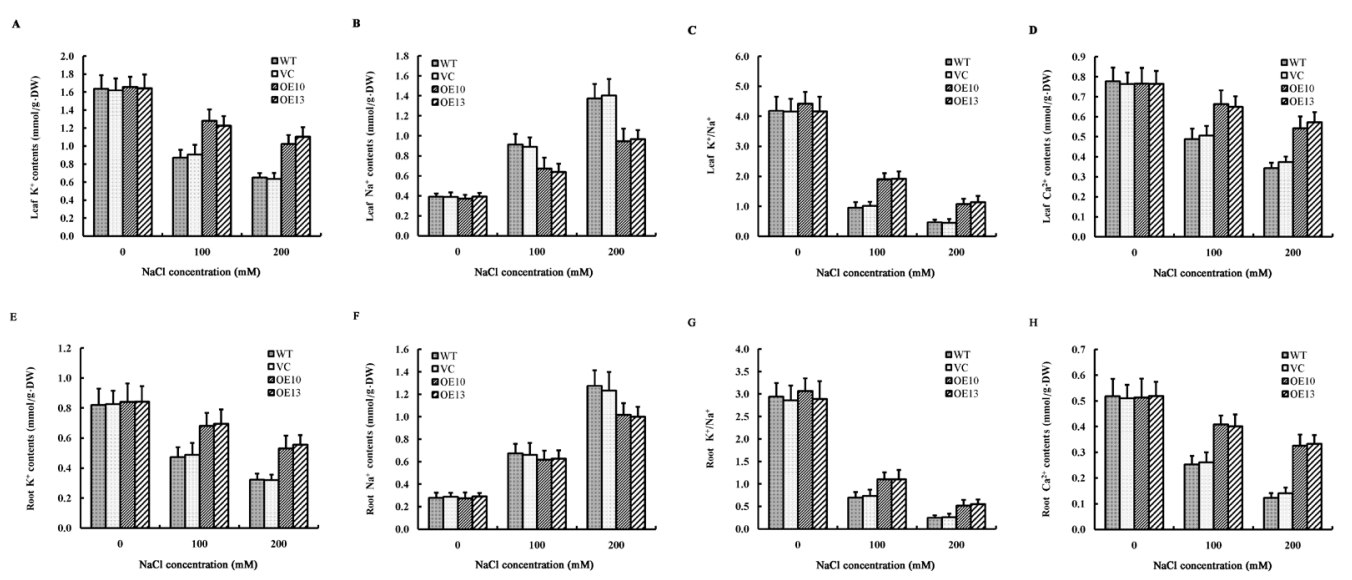

Figure 3. Effects of $\mathrm{NaCl}$ treatment on $\mathrm{K}^{+}(\mathbf{A}$ and $\mathbf{E}), \mathrm{Na}^{+}(\mathbf{B}$ and $\mathbf{F}), \mathrm{Ca}^{2+}(\mathbf{D}$ and $\mathbf{H})$ levels and $\mathrm{K}^{+} / \mathrm{Na}^{+}(\mathbf{C}$ and $\mathbf{G})$ ratio in tomato leaves and roots. Values are reported as means \pm SD from three replicates. DW: dry weight. For other abbreviations, see legend to Figure 1. 
After the 4-day exposure to $100 \mathrm{mM} \mathrm{NaCl}$, the net photosynthetic rate (Figure 4A) and the $F_{v} / F_{m}$ ratios of photosystem II (Figure 4B) in the control plants decreased more than the $\mathrm{OE}$ lines. Following the $200 \mathrm{mM} \mathrm{NaCl}$ treatment, photosynthetic activity had almost ceased in the control plants and their $F_{v} / F_{m}$ ratios declined to 0.1-0.2. At the same time, the OE lines maintained their photosynthetic activity and the $F_{v} / F_{m}$ ratio had only declined to 0.6 (Figure 4B). Thus, constitutive expression of ER-sHSP reduced photosystem damage under salt stress. Compared to the control plants, $\mathrm{OE}$ lines had greater leaf $g_{s}$ and transpiration rate at all time points (Figure 4).

$\mathbf{A}$

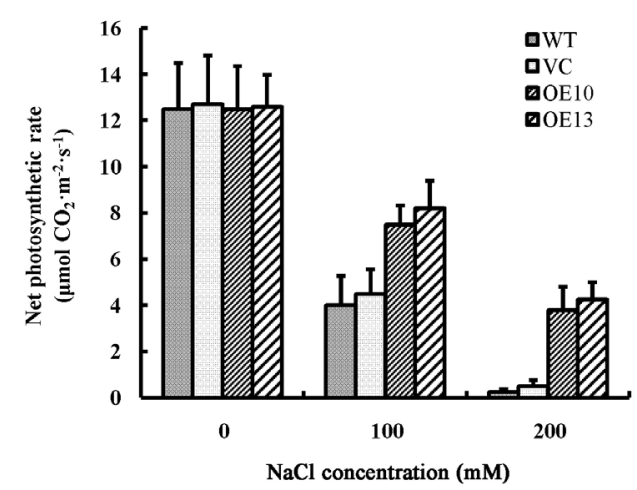

C

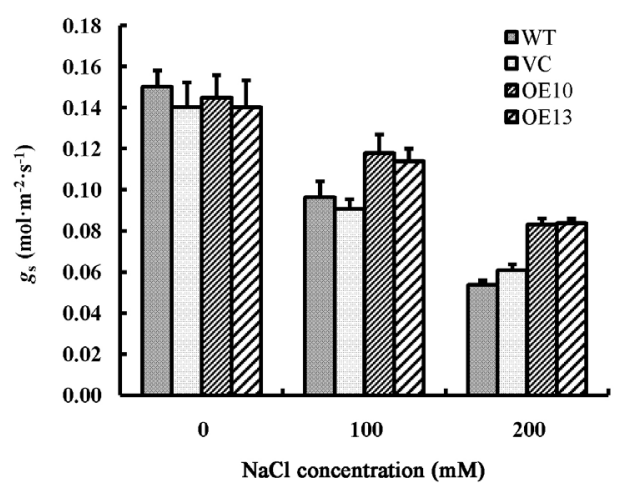

B

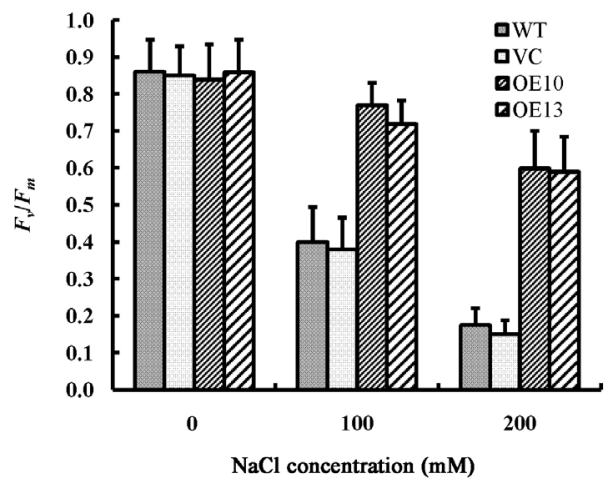

D

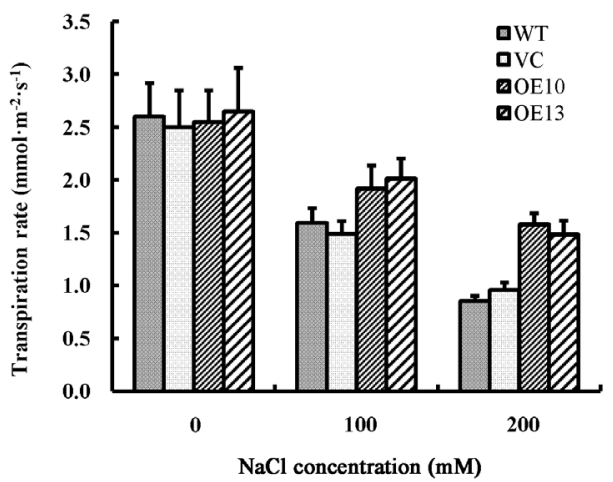

Figure 4. Net photosynthetic rate (A), maximum quantum yield of photosystem II photochemistry $\left(F_{v} / F_{m} ; \mathbf{B}\right)$, stomatal conductance $\left(g_{s} ; \mathbf{C}\right)$, and transpiration rate of tomato leaves $(\mathbf{D})$. Values are reported as means \pm SD from three replicates. For abbreviations, see legend to Figure 1.

Under salt stress, OE lines accumulated more osmolytes and soluble sugars than control plants (Figure 5). The large accumulation of osmolytes in the OE lines is associated with non-wilting leaves that have higher water content. 

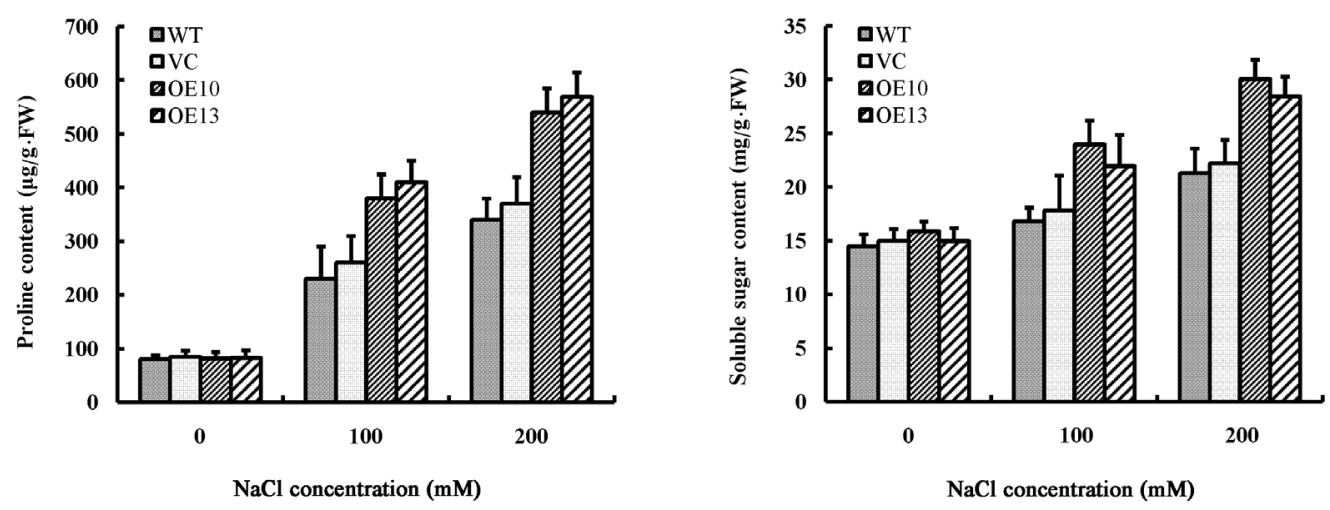

Figure 5. Salt-induced accumulation of proline and soluble sugars. Proline (A) and soluble sugar (B) content of tomato leaves. Values are reported as means $\pm \mathrm{SD}$ from three replicates. $\mathrm{FW}=$ fresh weight. For other abbreviations, see legend to Figure 1.

The high salt stress-induced expression of BiP, PDI, calnexin, and calreticulin increased in all plants, but this increase was less evident in the OE line plants compared to the control plants (Figure 6).

A

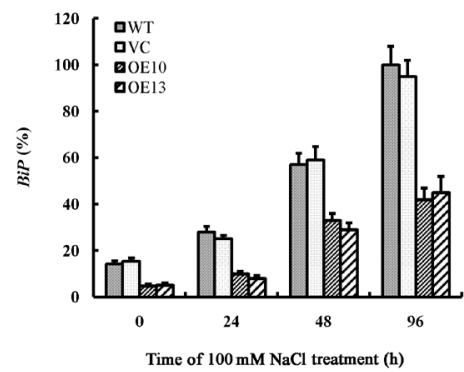

$\mathbf{C}$

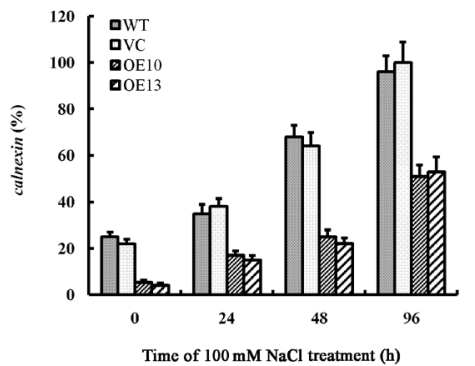

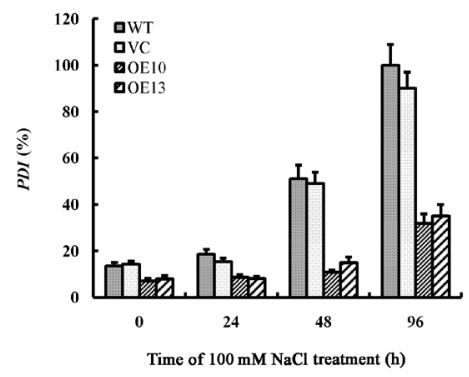

D

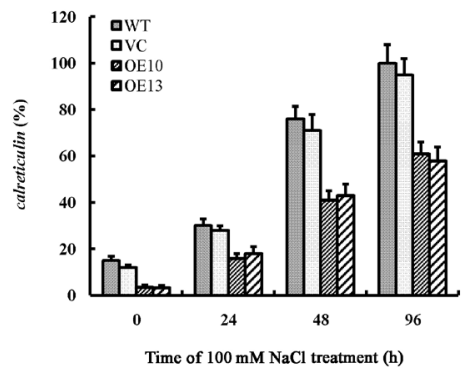

Figure 6. Expression of UPR responsive genes under salt stress. Relative expression levels of BiP (A), PDI (B), calnexin (C), and calreticulin (D) as determined by quantitative real-time PCR analysis. Within each gene, the maximum was normalized to $100 \%$ and the rest were scaled in proportion. Values are reported as means $\pm \mathrm{SD}$ from five replicates. For abbreviations, see legend to Figure 1. 


\section{DISCUSSION}

Tunicamycin blocks glycosylation and DTT alters the redox environment in the ER. Both can trigger the UPR and induce expression of chaperones and foldases (Mori et al., 1992; Travers et al., 2000). Environmental stress can also affect the ER. Drought stress can increase the expression of BiP and calreticulin (Cascardo et al., 2000; Jia et al., 2008). Salt stress can also upregulate BiP transcription (Liu et al., 2011). If plant cells have a defect in the UPR signal pathway, salt stress can provoke a stronger UPR and greatly boost BiP expression (Howell, 2013). In contrast, overexpression of ER molecular chaperones has been shown to relieve stress under extreme abiotic conditions (Alvim et al., 2001; Jia et al., 2008; Valente et al., 2009). Previously, it has been demonstrated that ER-sHSP reduces ER stress in tomato plants (Zhao et al., 2007). In the present experiment, OE lines were shown to have increased salinity tolerance and reduced UPR, as indicated by the lower expression of ER resident molecular chaperones.

$\mathrm{BiP}$ is the most abundant chaperone in the ER and it is often used as a molecular marker of ER stress (Kamauchi et al., 2005). For ER protein mutants, fluctuating BiP levels do not correlate with changes in salinity tolerance. For example, under $\mathrm{NaCl}$ stress, $h r d 3 a$ and stt $3 a$ increased the expression of BiP (Koiwa et al., 2003; Liu et al., 2011), atztp29 downregulated the level of BiP (Wang et al., 2010), whereas the BiP content in atbzip 17 remained unchanged (Liu et al., 2007b). In the present experiment, overexpression of ER-sHSP depressed the saltinduced expression of $\mathrm{BiP}$ and PDI, but $\mathrm{OE}$ lines still displayed improved $\mathrm{NaCl}$ tolerance. This indicates that the interaction between the UPR pathway and the salt stress response pathway is complex (Humbert et al., 2012).

BiP transgenic soybean (Alvim et al., 2001; Valente et al., 2009) and ER-sHSP transgenic tomato plants both have improved tolerance to salt stress. However, each has a distinctive phenotype and different physiological changes occur in the two plant species. Under salt stress, the roots of ER-sHSP OE lines were more robust and had a greater biomass than control plants (Figure 2). In contrast, the roots of BiP transgenic soybeans were smaller than WT plants (Valente et al., 2009). Under NaCl stress, ER-sHSP OE lines had increased accumulation of osmolytes, such as proline, soluble sugars, and $\mathrm{K}^{+}$ions (Figures 3 and 5), whereas the osmolyte level in BiP transgenic soybean was unchanged (Valente et al., 2009). With the vigorous root system and the large accumulation of osmolytes, ER-sHSP OE lines were able to absorb and hold more water. In addition, constitutive expression of ER-sHSP reduced salt damage to the photosystem (Figure 4). These findings explain why the ER-sHSP OE lines did not display a withered phenotype even under high salt stress.

\section{CONCLUSION}

In this study, the role of ER-sHSP in improving plant resistance to salt stress was explored. The results showed that the constitutive expression of ER-sHSP significantly increased salinity tolerance in tomato plants and reduced the expression of ER resident molecular chaperones. We suggest that the incorporated ER-sHSP in the OE lines performed functions that normally are performed by ER molecular chaperones such as BiP.

\section{Conflicts of interest}

The authors declare no conflict of interest. 


\title{
ACKNOWLEDGMENTS
}

\author{
Research supported by the National Natural Science Foundation of China (Grant \\ \#31270298).
}

\section{REFERENCES}

Alvim FC, Carolino SM, Cascardo JC, Nunes CC, et al. (2001). Enhanced accumulation of BiP in transgenic plants confers tolerance to water stress. Plant Physiol. 126: 1042-1054. http://dx.doi.org/10.1104/pp.126.3.1042

Bates LS, Waldren RP and Teare ID (1973). Rapid determination of free proline for water-stress studies. Plant Soil 39: 205-207. http://dx.doi.org/10.1007/BF00018060

Brodsky JL and McCracken AA (1999). ER protein quality control and proteasome-mediated protein degradation. Semin. Cell Dev. Biol. 10: 507-513. http://dx.doi.org/10.1006/scdb.1999.0321

Cascardo JC, Almeida RS, Buzeli RA, Carolino SM, et al. (2000). The phosphorylation state and expression of soybean $\mathrm{BiP}$ isoforms are differentially regulated following abiotic stresses. J. Biol. Chem. 275: 14494-14500. http://dx.doi. org/10.1074/jbc.275.19.14494

Gething MJ (1999). Role and regulation of the ER chaperone BiP. Semin. Cell Dev. Biol. 10: 465-472. http://dx.doi. org/10.1006/scdb.1999.0318

Halperin L, Jung J and Michalak M (2014). The many functions of the endoplasmic reticulum chaperones and folding enzymes. IUBMB Life 66: 318-326. http://dx.doi.org/10.1002/iub.1272

Howell SH (2013). Endoplasmic reticulum stress responses in plants. Annu. Rev. Plant Biol. 64: 477-499. http://dx.doi. org/10.1146/annurev-arplant-050312-120053

Humbert S, Zhong S, Deng Y, Howell SH, et al. (2012). Alteration of the bZIP60/IRE1 pathway affects plant response to ER stress in Arabidopsis thaliana. PLoS One 7: e39023. http://dx.doi.org/10.1371/journal.pone.0039023

Jia XY, Xu CY, Jing RL, Li RZ, et al. (2008). Molecular cloning and characterization of wheat calreticulin (CRT) gene involved in drought-stressed responses. J. Exp. Bot. 59: 739-751. http://dx.doi.org/10.1093/jxb/erm369

Kamauchi S, Nakatani H, Nakano C and Urade R (2005). Gene expression in response to endoplasmic reticulum stress in Arabidopsis thaliana. FEBS J. 272: 3461-3476. http://dx.doi.org/10.1111/j.1742-4658.2005.04770.x

Koiwa H, Li F, McCully MG, Mendoza I, et al. (2003). The STT3a subunit isoform of the Arabidopsis oligosaccharyltransferase controls adaptive responses to salt/osmotic stress. Plant Cell 15: 2273-2284. http://dx.doi. org/10.1105/tpc.013862

Li XG, Meng QW, Jiang GQ and Zou Q (2003). The susceptibility of cucumber and sweet pepper to chilling under low irradiance is related to energy dissipation and water-water cycle. Photosynthetica 41: 259-265. http://dx.doi. org/10.1023/B:PHOT.0000011959.30746.c0

Ling SP, Su SS, Zhang HM, Zhang XS, et al. (2014). Molecular cloning and characterization of the full-length Hsp90 gene from Matricaria recutita. Genet. Mol. Res. 13: 10994-11003. http://dx.doi.org/10.4238/2014.December.19.22

Liu JX and Howell SH (2010). Endoplasmic reticulum protein quality control and its relationship to environmental stress responses in plants. Plant Cell 22: 2930-2942. http://dx.doi.org/10.1105/tpc.110.078154

Liu JX, Srivastava R, Che P and Howell SH (2007a). Salt stress responses in Arabidopsis utilize a signal transduction pathway related to endoplasmic reticulum stress signaling. Plant J. 51: 897-909. http://dx.doi.org/10.1111/j.1365313X.2007.03195.X

Liu JX, Srivastava R, Che P and Howell SH (2007b). An endoplasmic reticulum stress response in Arabidopsis is mediated by proteolytic processing and nuclear relocation of a membrane-associated transcription factor, bZIP28. Plant Cell 19: 4111-4119. http://dx.doi.org/10.1105/tpc.106.050021

Liu L, Cui F, Li Q, Yin B, et al. (2011). The endoplasmic reticulum-associated degradation is necessary for plant salt tolerance. Cell Res. 21: 957-969. http://dx.doi.org/10.1038/cr.2010.181

Mamedov TG and Shono M (2008). Molecular chaperone activity of tomato (Lycopersicon esculentum) endoplasmic reticulum-located small heat shock protein. J. Plant Res. 121: 235-243. http://dx.doi.org/10.1007/s10265-008-0148-x

Marschner H, Kuiper PJC and Kylin A (1981). Genotypic differences in the response of sugar beet plants to replacement of potassium by sodium. Physiol. Plant. 51: 239-244. http://dx.doi.org/10.1111/j.1399-3054.1981.tb02705.x

Martínez IM and Chrispeels MJ (2003). Genomic analysis of the unfolded protein response in Arabidopsis shows its connection to important cellular processes. Plant Cell 15: 561-576. http://dx.doi.org/10.1105/tpc.007609

Mori K, Sant A, Kohno K, Normington K, et al. (1992). A 22 bp cis-acting element is necessary and sufficient for the induction of the yeast KAR2 (BiP) gene by unfolded proteins. EMBO J. 11: 2583-2593. 
Noiva R (1999). Protein disulfide isomerase: the multifunctional redox chaperone of the endoplasmic reticulum. Semin. Cell Dev. Biol. 10: 481-493. http://dx.doi.org/10.1006/scdb.1999.0319

Ozgur R, Turkan I, Uzilday B and Sekmen AH (2014). Endoplasmic reticulum stress triggers ROS signalling, changes the redox state, and regulates the antioxidant defence of Arabidopsis thaliana. J. Exp. Bot. 65: 1377-1390. http://dx.doi. org/10.1093/jxb/eru034

Schröder M and Kaufman RJ (2005). ER stress and the unfolded protein response. Mutat. Res. 569: 29-63. http://dx.doi. org/10.1016/j.mrfmmm.2004.06.056

Travers KJ, Patil CK, Wodicka L, Lockhart DJ, et al. (2000). Functional and genomic analyses reveal an essential coordination between the unfolded protein response and ER-associated degradation. Cell 101: 249-258. http://dx.doi. org/10.1016/S0092-8674(00)80835-1

Valente MA, Faria JA, Soares-Ramos JR, Reis PA, et al. (2009). The ER luminal binding protein (BiP) mediates an increase in drought tolerance in soybean and delays drought-induced leaf senescence in soybean and tobacco. J. Exp. Bot. 60: 533-546. http://dx.doi.org/10.1093/jxb/ern296

Wan S and Jiang L (2015). Endoplasmic reticulum (ER) stress and the unfolded protein response (UPR) in plants. Protoplasma 10.1007/s00709-015-0842-1.

Wang M, Xu Q, Yu J and Yuan M (2010). The putative Arabidopsis zinc transporter ZTP29 is involved in the response to salt stress. Plant Mol. Biol. 73: 467-479. http://dx.doi.org/10.1007/s11103-010-9633-4

Zhao C, Shono M, Sun A, Yi S, et al. (2007). Constitutive expression of an endoplasmic reticulum small heat shock protein alleviates endoplasmic reticulum stress in transgenic tomato. J. Plant Physiol. 164: 835-841. http://dx.doi. org/10.1016/j.jplph.2006.06.004 